\title{
ORIGINAL RESEARCH \\ Prevalence of 3 Healthy Lifestyle \\ Behaviors Among US Adults With and Without History of Stroke
}

\author{
Ryan R. Bailey, PhD, OTR/L ${ }^{1}$; Allison Phad, $\mathrm{MPH}^{1}$; Ryan McGrath, $\mathrm{PhD}^{2}$; \\ Rachel Tabak, PhD, RD ${ }^{1}$; Debra Haire-Joshu, PhD ${ }^{1}$
}

Accessible Version: www.cdc.gov/pcd/issues/2019/18_0409.htm

Suggested citation for this article: Bailey RR, Phad A, McGrath R, Tabak R, Haire-Joshu D. Prevalence of 3 Healthy Lifestyle Behaviors Among US Adults With and Without History of Stroke. Prev Chronic Dis 2019;16:180409. DOI: https:/doi.org/10.5888/ pcd16.180409.

\section{PEER REVIEWED}

\section{Summary}

What is already known on this topic?

Healthy lifestyle behaviors decrease risk for cardiometabolic conditions and recurrent stroke for adults with history of stroke.

\section{What is added by this report?}

This study updates and compares population-based estimates for 3 lifestyle behaviors - consuming 1 or more fruit and 1 or more vegetable daily, meeting weekly aerobic physical activity recommendations, and having a body mass index of less than $25 \mathrm{~kg} / \mathrm{m}^{2}$ - among adults with and without history of stroke.

\section{What are the implications for public health practice?}

Results indicate that adults with history of stroke report low fruit and vegetable consumption and physical activity, suggesting that additional health behavior interventions are needed.

\section{Abstract}

\section{Introduction}

Engaging in healthy lifestyle behaviors decreases risk for cardiometabolic complications, which is of particular concern for stroke survivors whose history of stroke (HOS) increases cardiometabolic risk. Population-based estimates of healthy behaviors in adults with HOS are lacking but could be used to inform research, policy, and health care practice. The objective of this study was to calculate and compare population-based estimates of the prevalence of consuming 1 or more fruit and 1 or more vegetable daily, meeting weekly aerobic physical activity recommendations, having a body mass index (BMI) of less than $25 \mathrm{~kg} / \mathrm{m}^{2}$, and the number of healthy behaviors among US adults with and without HOS.

\section{Methods}

We used data from the 2015 Behavioral Risk Factor Surveillance System. Weighted and age-adjusted (to the 2000 US standard population) prevalence estimates and adjusted odds ratios (AORs, adjusted for demographic variables) were computed for study variables.

\section{Results}

Adults with HOS were less likely than adults without HOS to consume 1 or more fruit and 1 or more vegetable daily $(\mathrm{AOR}=0.85$; $95 \%$ confidence interval $[\mathrm{CI}], 0.79-0.91)$, meet weekly aerobic physical activity recommendations $(\mathrm{AOR}=0.72 ; 95 \% \mathrm{CI}$, $0.67-0.78)$, and engage in $2(\mathrm{AOR}=0.86 ; 95 \% \mathrm{CI}, 0.79-0.94)$ or $3(\mathrm{AOR}=0.73 ; 95 \% \mathrm{CI}, 0.64-0.82)$ healthy behaviors. Adults with HOS were more likely to engage in 0 healthy behaviors (AOR $=1.26$; 95\% CI, 1.16-1.37). Having a BMI of less than 25 $\mathrm{kg} / \mathrm{m}^{2}$ and engaging in 1 healthy behavior were similar between groups.

\section{Conclusion}

Prevalence of individual and total number of healthy behaviors was lower in adults with HOS for several healthy behaviors. Future research, policy, and health care practice is needed to promote healthy behaviors in adults with HOS.

\section{Introduction}

Healthy lifestyle behaviors, including fruit and vegetable consumption, physical activity, and having a healthy weight, protect against many chronic conditions, including cancer, cardiovascular disease, diabetes, and stroke (1). Lifestyle modification interven- 
tions have demonstrated that lifestyle behavior modification can decrease cardiometabolic risk through improved blood pressure, blood cholesterol, triglycerides, blood glucose, and body weight (2-5). Improvements in these factors are pertinent to persons with history of stroke (HOS), because HOS increases risk for diabetes, recurrent stroke, and cardiovascular mortality $(6,7)$.

Common goals of lifestyle programs include weight loss through modification of dietary intake and physical activity. Weight loss of approximately $5 \%$ is sufficient to achieve improvement in cardiometabolic indices of health (eg, blood pressure, dyslipidemia, diabetes) (8). However, weight loss interventions among people with HOS are lacking even though weight loss is recommended for managing cardiometabolic risk factors common among people with HOS (8). Health promotion interventions in stroke survivors have demonstrated favorable improvements in both body weight and cardiometabolic risk $(9,10)$. Epidemiological investigation has also demonstrated a dose-response relationship where engaging in an increased number of healthy behaviors is associated with decreased all-cause and cardiovascular mortality in people with HOS (11).

Despite scientific evidence and clinical guidelines (6) that promote participation in healthy lifestyle behaviors after stroke, population-based estimates of the prevalence of healthy behaviors among people with HOS are lacking. A better understanding of such behaviors can inform future research, federal policy, and the development of lifestyle behavior modification interventions tailored for people with HOS. Therefore, the purpose of this study was to compare the prevalence of 3 healthy lifestyle behaviors (consuming fruits and vegetables, engaging in physical activity, and having a body mass index [BMI] $<25 \mathrm{~kg} / \mathrm{m}^{2}$ ) and the total number of healthy behaviors among US adults with and without HOS.

\section{Methods}

\section{Study population}

In this cross-sectional study, we analyzed data from the $2015 \mathrm{Be}-$ havioral Risk Factor Surveillance System (BRFSS) to examine healthy behaviors among adults with HOS, using adults without HOS as the reference group. The BRFSS is an ongoing, statebased, telephone survey that uses randomly selected landline and cellular telephone numbers to monitor behavioral risk factors among noninstitutionalized adults aged 18 years or older, and it includes data from all 50 states, the District of Columbia, Puerto Rico, and Guam. Median response rates in 2015 were $48.2 \%$ for landline and $47.2 \%$ for cellular telephone surveys, which are com- parable to response rates for other national telephone-based surveys. More information about the 2015 BRFSS is available (www.cdc.gov/brfss/annual_data/annual_2015.html).

Respondents were identified as having HOS by their response to the following BRFSS question: "Has a doctor, nurse, or other health professional ever told you that you had a stroke?" Of 441,456 respondents in the 2015 BRFSS, 1,290 individuals responded "don't know/not sure" or refused to answer and were excluded from analysis. This resulted in a study population of 440,166 respondents (HOS, $n=18,269$; no HOS, $n=421,897$ ).

\section{Demographic characteristics and health conditions}

Demographic characteristics were sex (male/female), age in years (18-24, 25-44, 45-64, $\geq 65$ ), race/ethnicity (non-Hispanic white, non-Hispanic black, Hispanic, other), marital status (married or part of an unmarried couple, previously married, never married), education (some high school, graduated high school, some college, graduated college), and annual household income $(<\$ 15,000$, $\$ 15,000$ to $<\$ 25,000, \$ 25,000$ to $<\$ 35,000, \$ 35,000$ to $<\$ 50,000$, $\geq \$ 50,000)$. Health conditions were presence of hypertension, high cholesterol, and diabetes. These health conditions were determined by respondents' responses to "Has a doctor, nurse, or other health professional ever told you that you had [condition]?" where the question was asked for each health condition.

\section{Study variables}

The 3 healthy behaviors assessed were self-reported fruit and vegetable consumption, self-reported physical activity, and having a BMI of less than $25 \mathrm{~kg} / \mathrm{m}^{2}$, which was calculated by using self-reported weight and height at the time of survey. BRFSS tracks fruit and vegetable consumption as a marker of nutritional intake in lieu of performing a comprehensive nutritional assessment. Respondents were asked to indicate how many times per day, week, or month (during the previous month) they consumed fruit, 100\% fruit juice, beans, and vegetables. BRFSS identifies individuals who consume 1 or more fruit and 1 or more vegetable daily, which was defined as a healthy behavior in this study, but does not track whether individuals meet national recommendations for fruit and vegetable consumption because recommendations are based on an individual's age, sex, and physical activity level rather than a specific number of servings (12). BRFSS also asks respondents to provide information on moderate- and vigorous-intensity physical activity other than regular job duties during the previous month, including exercise, leisure, and household physical activity. Meeting recommended levels of weekly aerobic physical activity was defined as accruing at least 150 minutes of moderate-intensity physical activity per week, at least 75 minutes of vigorous-intensity physical activity per week, or an equivalent combination of

\footnotetext{
The opinions expressed by authors contributing to this journal do not necessarily reflect the opinions of the U.S. Department of Health and Human Services, the Public Health Service, the Centers for Disease Control and Prevention, or the authors' affiliated institutions.
} 
moderate- and vigorous-intensity physical activity per week (13). Lastly, having a BMI less than $25 \mathrm{~kg} / \mathrm{m}^{2}$ was selected, because it is associated with decreased risk for chronic disease and all-cause mortality (14). We also computed the total number of healthy behaviors for each participant to examine clustering of healthy behaviors.

\section{Data analysis}

We used SAS for Windows, Version 9.4 (SAS Institute Inc) to analyze data and to account for the complex sampling design, including selection probability and survey nonresponse. Age-adjusted (to the 2000 US standard population) and weighted prevalence estimates with $95 \%$ confidence intervals (CIs) were calculated for demographic characteristics, health conditions, and study variables. For number of healthy behaviors, only respondents who provided data for all 3 healthy behaviors were analyzed. To examine the relationship of individual and number of healthy behaviors by HOS status, we used logistic regression to compute unadjusted odds ratios (ORs) with HOS status as a predictor in the model. Adjusted ORs, controlling for demographic variables (ie, sex, age, race/ethnicity, marital status, education, and annual household income) were also calculated. $P$ values were not reported because most variables were significant as a result of the large sample size obtained when we weighted the data (15), but significance can be inferred by examining overlap of $95 \%$ CIs (16).

\section{Results}

Most respondents were female, aged 45 to 65 years, non-Hispanic white, married or part of an unmarried couple, had attended college, and had an annual household income of $\$ 50,000$ or more (Table 1). Respondents with HOS were older and had lower income than respondents with no HOS. Most respondents with HOS were aged 65 years or older and had an annual household income of $\$ 15,000$ to less than $\$ 25,000$. In contrast, most respondents without HOS were aged 25 to 44 years and had an annual household income of $\$ 50,000$ or more. Respondents with HOS had a higher prevalence of hypertension, high cholesterol, and diabetes than respondents with no HOS.

The prevalence of 2 healthy behaviors - consuming 1 or more fruit and 1 or more vegetable daily and meeting weekly aerobic physical activity recommendations - was approximately $50 \%$ among respondents as a whole (Table 2). However, prevalence for these 2 healthy behaviors was lower among respondents with HOS than respondents without HOS $-45.2 \%$ versus $52.0 \%$ for fruit and vegetable consumption and $42.5 \%$ versus $50.9 \%$ for meeting weekly physical activity recommendations. Approximately onethird of respondents had a BMI of less than $25 \mathrm{~kg} / \mathrm{m}^{2}$, regardless of HOS status.
Before adjustment, respondents with HOS had lower odds of engaging in each healthy behavior compared with respondents without HOS (Figure). After adjustment for demographic characteristics, only the difference in having a BMI $<25 \mathrm{~kg} / \mathrm{m}^{2}$ between groups was attenuated.

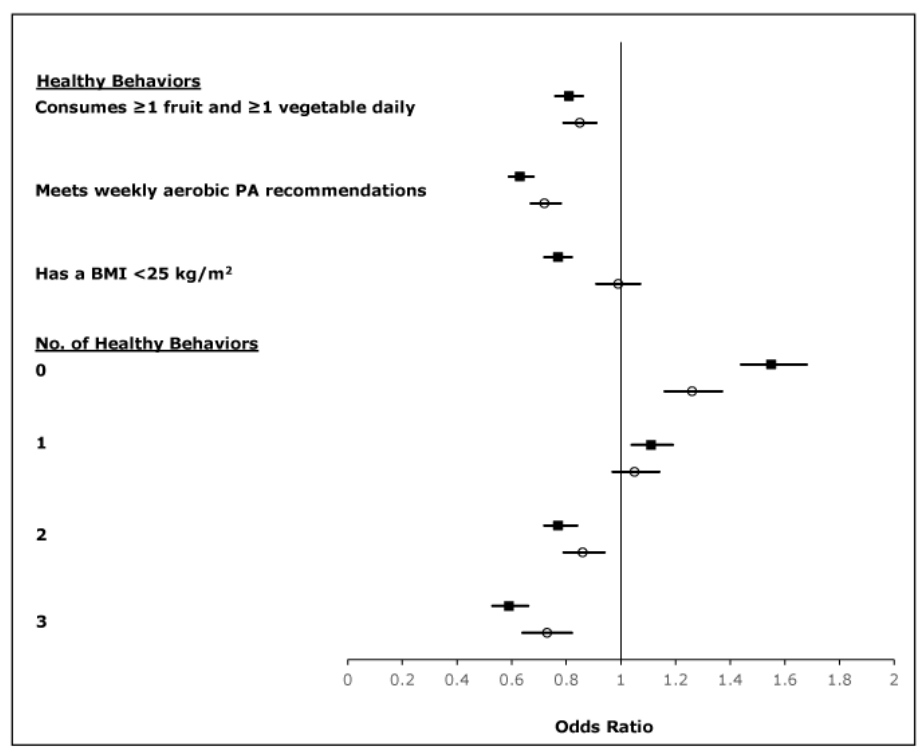

Figure. Crude and adjusted odds of individual and total number of healthy behaviors in adults with history of stroke (HOS), 2015 Behavioral Risk Factor Surveillance System. Adults without HOS was the reference group. Sex, age, race/ethnicity, marital status, education, and annual household income were controlled for in the adjusted odds. Black squares represent crude values, and open circles represent adjusted values; horizontal bars represent 95\% confidence intervals.

Data for all 3 healthy behaviors were available from 346,930 respondents (HOS, $\mathrm{n}=13,917$; no HOS: $\mathrm{n}=333,013$ ) for analysis. The age-adjusted, estimated prevalence of number of healthy behaviors indicated that respondents with HOS engaged in fewer healthy behaviors than did respondents without HOS (Table 3). The prevalence of (or the proportion of) not engaging in any healthy behavior was higher ( $24.8 \%$ vs $18.8 \%)$ and the prevalence of engaging in 3 healthy behaviors was lower ( $8.1 \%$ vs $12.7 \%)$ in respondents with HOS compared with respondents without HOS. Similarly, the odds of not engaging in any healthy behavior were higher in respondents with HOS compared with respondents without $\mathrm{HOS}(\mathrm{OR}=1.26 ; 95 \% \mathrm{CI}, 1.16-1.37)$, while odds of engaging in $2(\mathrm{OR}=0.86 ; 95 \% \mathrm{CI}, 0.79-0.94)$ or $3(\mathrm{OR}=0.73 ; 95 \%$ CI, 0.64-0.82) healthy behaviors were lower, even after adjusting for demographic characteristics (Figure).

The opinions expressed by authors contributing to this journal do not necessarily reflect the opinions of the U.S. Department of Health and Human Services, the Public Health Service, the Centers for Disease Control and Prevention, or the authors' affiliated institutions. 


\section{Discussion}

We found that, compared with adults without HOS, adults with HOS had lower odds of consuming 1 or more fruit and 1 or more vegetable daily and meeting weekly aerobic physical activity recommendations. Furthermore, adults with HOS had higher odds of not engaging in any healthy behavior and lower odds of engaging in 2 or 3 healthy behaviors than adults without HOS. These results highlight disparities in healthy behaviors between adults with and without HOS, which is concerning for stroke survivors who already have increased cardiometabolic risk.

Despite recommendations for people with HOS to engage in healthy behaviors to reduce risk of chronic disease and secondary conditions, little is known about the prevalence of engaging in healthy behaviors in this population or about weight loss interventions in people with HOS. No study with weight loss as the primary outcome has been published in people with HOS. Rather, interventions intended to promote health or manage risk factors have tracked weight as a secondary outcome. Rimmer et al demonstrated a modest weight loss of $1.27 \mathrm{~kg}$ after a 12 -week, group-based intervention that consisted of exercise, nutrition education, and support for healthy behaviors change (10). Similarly, Joubert et al demonstrated a 0.5 reduction in BMI (equivalent to a loss of $0.68 \mathrm{~kg}$ in a person that weighs $90.7 \mathrm{~kg}$ and is $1.75 \mathrm{~m}$ tall) in a sample of adults with HOS who received telephone support from a nurse coordinator in advance of regularly scheduled visits with their primary care physician at 3, 6, 9, and 12 months after stroke (9). In both studies, weight loss occurred among stroke survivors with overweight or obesity in the context of interventions addressing lifestyle behaviors, including physical activity and nutritional intake. Furthermore, improvements in blood pressure and cholesterol were also observed. These studies demonstrate that weight loss can occur in conjunction with decreased cardiometabolic risk in overweight or obese people with HOS through modification of lifestyle behaviors. This is important because obesity increases cardiometabolic risk (8), which is present in $64 \%$ of adults with HOS as we report here.

Similarly, little is known about fruit and vegetable consumption in people with HOS. Studies that examine nutrition in people with HOS often investigate inadequate nutritional intake and have demonstrated that adults with dysphagia as well as communitydwelling adults with minor functional disability have decreased energy intake and protein consumption compared with adults without HOS (17-19). Surprisingly, fruit and vegetable consumption has received little attention among people with HOS. Using data from 388 stroke survivors obtained from the National Health and Nutrition Examination Survey between 1988 and 1994, Towfighi et al estimated that $98.1 \%$ of adult stroke survivors consume at least 1 serving of fruits or vegetables daily (11). This estimated prevalence is much higher than the $45.2 \%$ reported in this study, which may be explained by the difference in the number of study respondents with HOS $(\mathrm{n}=388$ vs $\mathrm{n}=18,269)$ and because Towfighi et al measured fruit or vegetable consumption rather than fruit and vegetable consumption. Although our measure of fruit and vegetable consumption provides only a snapshot of one's dietary intake, it is an important measure for at least 2 reasons. First, fruit and vegetable consumption is a known protector against stroke, where as few as 3 servings can reduce risk of stroke by $11 \%$ (20). Second, measuring low fruit and vegetable consumption is important for identifying individuals at risk for underconsumption of important nutrients that protect against chronic conditions (12). As it relates to this study, $54.8 \%$ of adults with HOS and $48 \%$ of adults without HOS reported consuming less than 1 fruit and 1 vegetable daily, which places these individuals at increased nutritional risk.

In our study, adults with HOS had $28 \%$ lower odds of meeting weekly aerobic physical activity recommendations compared with adults without HOS. These findings mirror many study results showing that physical activity is lower in people with HOS. In a recent systematic review, English et al reported that daily step counts among people with HOS were less than half those of agematched controls, but studies reporting activity intensity were sparse (21). More recently, 2 cohort studies reported an average of 4.9 (standard deviation, 5.8) minutes (22) and 66 (standard deviation, 68) minutes (23) of moderate-to-vigorous physical activity daily among community-dwelling adults with HOS, with respective samples sizes of 37 and 25. Given the variability in minutes of physical activity between studies and standard deviations within studies, it is apparent that physical activity varies among individuals with HOS such that some individuals are very active while others are not, and that HOS by itself is not the only limiter of physical activity. In our study, $42.5 \%$ of adults with HOS reported meeting weekly aerobic physical activity recommendations, which is encouraging. The high prevalence was likely due to the inclusion on the BRFSS of leisure and household physical activity, in addition to exercise, in its calculation of aerobic physical activity.

Interventions for secondary stroke risk management have been tested, but outcomes related to changes in weight, fruit and vegetable intake, and physical activity have demonstrated limited effectiveness (24). Many of the tested interventions have been limited in duration and intensity, with many lasting less than 3 months and consisting of only 6 to 12 visits. In contrast, guidelines for the management of overweight and obesity in adults advise that lifestyle modification programs are most effective when 14 or more visits occur over 6 months or more and when caloric intake and physical activity are modified through use of behavior change

\footnotetext{
The opinions expressed by authors contributing to this journal do not necessarily reflect the opinions of the U.S. Department of Health and Human Services, the Public Health Service, the Centers for Disease Control and Prevention, or the authors' affiliated institutions.
} 
strategies (14). Failure to follow these guidelines may explain why previous secondary stroke prevention programs have demonstrated limited effectiveness, whereas programs such as the Diabetes Prevention Program (2) and the Stenting versus Aggressive Medical Management for Preventing Recurrent Stroke in Intracranial Stenosis (SAMMPRIS) trial (3) have demonstrated much greater effectiveness. Because adjusted odds of not having any healthy behavior was higher and adjusted odds of 2 or 3 healthy behaviors were lower among adults with HOS in our study, adults with HOS would likely benefit from lifestyle behavior modification programs that are consistent with recommended guidelines for weight loss in terms of content, duration, and intensity.

Our study has several limitations. First, BRFSS is a self-report survey, so responses are subject to reporting bias; despite this limitation, BRFSS collects data from US adults in each state and territory, which are weighted to match known sample distributions and demographic characteristics, for disease surveillance and public health promotion. Second, BRFSS is a telephone survey conducted among noninstitutionalized, US adults; therefore, reports from individuals not living in the community or respondents with HOS whose cognitive or physical limitations interfered with their ability to participate in the survey may not be represented. Additionally, BRFSS does not collect information on stroke characteristics (eg, time since stroke, number of strokes, stroke severity), so examination of healthy behaviors among stroke subpopulations was not possible. Third, the cross-sectional nature of the study prevents determination of causality among healthy behaviors, HOS status, and demographic characteristics. Despite these limitations, reliability and validity of BRFSS questions and methodology are adequate (25). Furthermore, because BRSSS is a statebased survey conducted in all 50 states, the District of Columbia, and 3 US territories, the large sample size allowed for prevalence estimation of selected healthy behaviors among US adults with and without HOS.

Compared with adults without HOS, adults with HOS are less likely to consume at least 1 fruit and 1 vegetable daily, meet weekly aerobic physical activity recommendations, and engage in more than 1 healthy behavior. Engaging in healthy behaviors is important, because they reduce risk for recurrent stroke, development of comorbid conditions, and premature death, which is particularly important for stroke survivors, who are already at increased risk for these conditions as a result of previous stroke. Lifestyle interventions in this population are lacking but have potential to improve health and health-related quality of life. To this end, more research and lifestyle interventions are needed to address these disparities in healthy behaviors in adults with HOS.

\section{Acknowledgments}

The authors report no conflicts of interest. This work was supported by the National Institutes of Health (NIH) under grant no. P30DK092950 and grant no. 5T32HL130357-02; its contents are solely the responsibility of the authors and do not necessarily represent the official views of the NIH. No copyrighted materials (eg figures, surveys, instruments) were used in this study.

\section{Author Information}

Corresponding Author: Ryan R. Bailey, PhD, OTR/L, Washington University in St Louis, Brown School, Campus Box 1196, One Brookings Dr, St Louis, MO 63110. Telephone: 314-935-3073. Email: baileyr@wustl.edu.

Author Affiliations: ${ }^{1}$ Washington University in St Louis, St Louis, Missouri. ${ }^{2}$ North Dakota State University, Fargo, North Dakota.

\section{References}

1. Millen BE, Abrams S, Adams-Campbell L, Anderson CAM, Brenna JT, Campbell WW, et al. The 2015 Dietary Guidelines Advisory Committee scientific report: development and major conclusions. Adv Nutr 2016;7(3):438-44.

2. Knowler WC, Barrett-Connor E, Fowler SE, Hamman RF, Lachin JM, Walker EA, et al.; Diabetes Prevention Program Research Group. Reduction in the incidence of type 2 diabetes with lifestyle intervention or metformin. N Engl J Med 2002; 346(6):393-403.

3. Chimowitz MI, Lynn MJ, Derdeyn CP, Turan TN, Fiorella D, Lane BF, et al.; SAMMPRIS Trial Investigators. Stenting versus aggressive medical therapy for intracranial arterial stenosis. N Engl J Med 2011;365(11):993-1003.

4. Orchard TJ, Temprosa M, Barrett-Connor E, Fowler SE, Goldberg RB, Mather KJ, et al.; Diabetes Prevention Program Outcomes Study Research Group. Long-term effects of the Diabetes Prevention Program interventions on cardiovascular risk factors: a report from the DPP Outcomes Study. Diabet Med 2013;30(1):46-55.

5. Eckel RH, Jakicic JM, Ard JD, de Jesus JM, Houston Miller N, Hubbard VS, et al.; American College of Cardiology/American Heart Association Task Force on Practice Guidelines. 2013 AHA/ACC guideline on lifestyle management to reduce cardiovascular risk: a report of the American College of Cardiology/American Heart Association Task Force on Practice Guidelines. J Am Coll Cardiol 2014;63(25 Pt B,25 Part B):2960-84.

\footnotetext{
The opinions expressed by authors contributing to this journal do not necessarily reflect the opinions of the U.S. Department of Health and Human Services, the Public Health Service, the Centers for Disease Control and Prevention, or the authors' affiliated institutions.
} 
6. Kernan WN, Ovbiagele B, Black HR, Bravata DM, Chimowitz MI, Ezekowitz MD, et al.; American Heart Association Stroke Council, Council on Cardiovascular and Stroke Nursing, Council on Clinical Cardiology, and Council on Peripheral Vascular Disease. Guidelines for the prevention of stroke in patients with stroke and transient ischemic attack: a guideline for healthcare professionals from the American Heart Association/American Stroke Association. Stroke 2014; 45(7):2160-236.

7. Benjamin EJ, Virani SS, Callaway CW, Chamberlain AM, Chang AR, Cheng S, et al.; American Heart Association Council on Epidemiology and Prevention Statistics Committee and Stroke Statistics Subcommittee. Heart disease and stroke statistics - 2018 update: a report from the American Heart Association. Circulation 2018;137(12):e67-492.

8. Klein S, Burke LE, Bray GA, Blair S, Allison DB, Pi-Sunyer $\mathrm{X}$, et al.; American Heart Association Council on Nutrition, Physical Activity, and Metabolism. Clinical implications of obesity with specific focus on cardiovascular disease: a statement for professionals from the American Heart Association Council on Nutrition, Physical Activity, and Metabolism: endorsed by the American College of Cardiology Foundation. Circulation 2004;110(18):2952-67.

9. Joubert J, Reid C, Barton D, Cumming T, McLean A, Joubert $\mathrm{L}$, et al. Integrated care improves risk-factor modification after stroke: initial results of the Integrated Care for the Reduction of Secondary Stroke model. J Neurol Neurosurg Psychiatry 2009;80(3):279-84.

10. Rimmer JH, Braunschweig C, Silverman K, Riley B, Creviston T, Nicola T. Effects of a short-term health promotion intervention for a predominantly African-American group of stroke survivors. Am J Prev Med 2000;18(4):332-8.

11. Towfighi A, Markovic D, Ovbiagele B. Impact of a healthy lifestyle on all-cause and cardiovascular mortality after stroke in the USA. J Neurol Neurosurg Psychiatry 2012; 83(2):146-51.

12. Centers for Disease Control and Prevention. Surveillance of fruit and vegetable intake using the Behavioral Risk Factor Surveillance System. https://www.cdc.gov/brfss/pdf/fruits_ vegetables.pdf. Accessed August 6, 2018.

13. US Department of Health and Human Services. Office of Disease Prevention and health Promotion. Physical activity guidelines. https://health.gov/paguidelines/guidelines/ adults.aspx. Accessed August 6, 2018.
14. Jensen MD, Ryan DH, Apovian CM, Ard JD, Comuzzie AG, Donato KA, et al.; American College of Cardiology/American Heart Association Task Force on Practice Guidelines; Obesity Society. 2013 AHA/ACC/TOS guideline for the management of overweight and obesity in adults: a report of the American College of Cardiology/American Heart Association Task Force on Practice Guidelines and The Obesity Society. J Am Coll Cardiol 2014;63(25 Pt B,25 Part B):2985-3023.

15. Lin M, Lucas HC, Shmueli G. Research commentary - too big to fail: large samples and the p-value problem. Inf Syst Res 2013;24(4):906-17.

16. Tryon WW. Evaluating statistical difference, equivalence, and indeterminacy using inferential confidence intervals: an integrated alternative method of conducting null hypothesis statistical tests. Psychol Methods 2001;6(4):371-86.

17. Kumlien S, Axelsson K. Stroke patients in nursing homes: eating, feeding, nutrition and related care. J Clin Nurs 2002; 11(4):498-509.

18. Perry L, McLaren S. An exploration of nutrition and eating disabilities in relation to quality of life at 6 months post-stroke. Health Soc Care Community 2004;12(4):288-97.

19. Westergren A. Nutrition and its relation to mealtime preparation, eating, fatigue and mood among stroke survivors after discharge from hospital - a pilot study. Open Nurs J 2008;2(1):15-20.

20. He FJ, Nowson CA, MacGregor GA. Fruit and vegetable consumption and stroke: meta-analysis of cohort studies. Lancet 2006;367(9507):320-6.

21. English C, Manns PJ, Tucak C, Bernhardt J. Physical activity and sedentary behaviors in people with stroke living in the community: a systematic review. Phys Ther 2014; 94(2):185-96.

22. English C, Healy GN, Coates A, Lewis L, Olds T, Bernhardt J. Sitting and activity time in people with stroke. Phys Ther 2016; 96(2):193-201.

23. Moore SA, Hallsworth K, Plötz T, Ford GA, Rochester L, Trenell MI. Physical activity, sedentary behaviour and metabolic control following stroke: a cross-sectional and longitudinal study. PLoS One 2013;8(1):e55263.

24. Lawrence M, Pringle J, Kerr S, Booth J, Govan L, Roberts NJ. Multimodal secondary prevention behavioral interventions for TIA and stroke: a systematic review and meta-analysis. PLoS One 2015;10(3):e0120902.

25. Pierannunzi C, Hu SS, Balluz L. A systematic review of publications assessing reliability and validity of the Behavioral Risk Factor Surveillance System (BRFSS), 2004-2011. BMC Med Res Methodol 2013;13(1):49.

The opinions expressed by authors contributing to this journal do not necessarily reflect the opinions of the U.S. Department of Health and Human Services, the Public Health Service, the Centers for Disease Control and Prevention, or the authors' affiliated institutions. 


\section{Tables}

Table 1. Demographic Characteristics and Health Conditions Among US Adults, by History of Stroke Status ${ }^{a}$, Behavioral Risk Factor Surveillance System, 2015

\begin{tabular}{|c|c|c|c|c|}
\hline \multirow[b]{2}{*}{ Characteristic } & \multirow{2}{*}{$\begin{array}{l}\text { Number of } \\
\text { Respondents }\end{array}$} & Total & $\begin{array}{l}\text { History of Stroke } \\
(n=18,269)\end{array}$ & $\begin{array}{l}\text { No History of Stroke } \\
(n=421,897)\end{array}$ \\
\hline & & \multicolumn{3}{|c|}{$\%(95 \% \text { Confidence Interval })^{c}$} \\
\hline \multicolumn{5}{|l|}{ Sex } \\
\hline Male & 186,362 & $48.9(48.6-49.2)$ & $46.4(43.3-49.4)$ & $48.9(48.6-49.2)$ \\
\hline Female & 253,804 & $51.1(50.8-51.4)$ & $53.6(50.6-56.7)$ & $51.1(50.8-51.5)$ \\
\hline \multicolumn{5}{|l|}{ Age, $y$} \\
\hline $18-24$ & 24,172 & $12.8(12.6-13.1)$ & $1.2(0.8-1.6)$ & $13.2(12.9-13.4)$ \\
\hline $25-44$ & 93,386 & $33.8(33.5-34.0)$ & $10.4(9.4-11.4)$ & $34.5(34.2-34.8)$ \\
\hline $45-64$ & 170,046 & $33.9(33.6-34.2)$ & $39.0(37.6-40.5)$ & $33.7(33.5-34.0)$ \\
\hline$\geq 65$ & 152,562 & $19.6(19.4-19.7)$ & $49.3(47.9-50.7)$ & $18.6(18.4-18.8)$ \\
\hline \multicolumn{5}{|l|}{ Race/ethnicity } \\
\hline Non-Hispanic white & 335,144 & $61.5(61.2-61.8)$ & $58.2(55.1-61.3)$ & $61.6(61.3-61.9)$ \\
\hline Non-Hispanic black & 34,267 & $11.7(11.5-11.9)$ & $18.1(15.6-20.7)$ & $11.5(11.3-11.8)$ \\
\hline Hispanic & 35,688 & $17.1(16.8-17.3)$ & $13.3(10.8-15.8)$ & $17.1(16.9-17.4)$ \\
\hline Other & 27,715 & $8.1(7.9-8.3)$ & $8.4(6.6-10.2)$ & $8.1(7.9-8.3)$ \\
\hline \multicolumn{5}{|l|}{ Marital status } \\
\hline Married or unmarried couple & 245,327 & $55.1(54.8-55.3)$ & $41.5(39.1-43.8)$ & $55.4(55.1-55.7)$ \\
\hline Previously married & 124,305 & $19.0(18.8-19.2)$ & $31.0(28.6-33.5)$ & $18.7(18.5-18.9)$ \\
\hline Never married & 67,503 & $25.2(25.0-25.5)$ & $26.6(24.1-29.2)$ & $25.2(25.0-25.4)$ \\
\hline \multicolumn{5}{|l|}{ Education } \\
\hline Some high school & 34,065 & $14.2(13.9-14.5)$ & $23.4(20.6-26.1)$ & $13.9(13.7-14.2)$ \\
\hline Graduated from high school & 122,846 & $27.9(27.6-28.1)$ & $29.8(27.2-32.3)$ & $27.8(27.5-28.1)$ \\
\hline Some college & 120,185 & $30.9(30.6-31.2)$ & $33.3(30.4-36.2)$ & $30.9(30.6-31.2)$ \\
\hline Graduated from college & 161,311 & $26.6(26.4-26.9)$ & $13.2(11.8-14.6)$ & $27.0(26.7-27.2)$ \\
\hline \multicolumn{5}{|l|}{ Annual household income, $\$$} \\
\hline$<15,000$ & 37,812 & $9.5(9.3-9.7)$ & $20.1(17.7-22.5)$ & $9.2(9.1-9.4)$ \\
\hline 15,000 to $<25,000$ & 58,976 & $14.1(13.9-14.3)$ & $23.7(20.9-26.5)$ & $13.9(13.7-14.1)$ \\
\hline 25,000 to $<35,000$ & 39,138 & $8.7(8.5-8.9)$ & $10.1(8.4-11.9)$ & $8.7(8.5-8.8)$ \\
\hline 35,000 to $<50,000$ & 51,949 & $11.3(11.1-11.5)$ & $8.85(7.4-10.3)$ & $11.3(11.1-11.5)$ \\
\hline$\geq 50,000$ & 173,229 & $39.2(38.9-39.5)$ & $19.6(17.1-22.1)$ & $39.8(39.5-40.1)$ \\
\hline Hypertension $^{a}$ & 177,434 & $29.9(29.6-30.1)$ & $58.1(55.0-61.1)$ & $29.1(28.9-29.4)$ \\
\hline High cholesterol $^{a}$ & 159,369 & $31.5(31.2-31.8)$ & $49.4(45.8-53.0)$ & $31.1(30.8-31.4)$ \\
\hline Diabetes $^{a}$ & 56,997 & $9.6(9.4-9.7)$ & $21.4(19.7-23.2)$ & $9.2(9.0-9.4)$ \\
\hline
\end{tabular}

a History of stroke, hypertension, high cholesterol, and diabetes were determined by respondents' response to "Has a doctor, nurse, or other health professional ever told you that that you had [condition]?" where the question was asked for each health condition.

${ }^{\mathrm{b}}$ Unweighted number of respondents. For demographic characteristics, categories may not sum to survey total because some respondents did not respond to all survey questions. For health characteristics, the number of respondents with the characteristic is reported.

${ }^{c}$ Estimates are weighted and age-adjusted to the 2000 US standard population, except for age groups, which display age group-specific percentages. Categories may not sum to $100 \%$ because some respondents did not respond to all survey questions.

The opinions expressed by authors contributing to this journal do not necessarily reflect the opinions of the U.S. Department of Health and Human Services, the Public Health Service, the Centers for Disease Control and Prevention, or the authors' affiliated institutions. 
Table 2. Prevalence of 3 Healthy Behaviors Among US Adults, by History of Stroke Status, Behavioral Risk Factor Surveillance System, 2015

\begin{tabular}{|c|c|c|c|c|}
\hline \multirow[b]{2}{*}{ Healthy Behavior } & \multirow{2}{*}{$\begin{array}{l}\text { Number of } \\
\text { Respondents }^{a}\end{array}$} & Total & $\begin{array}{l}\text { History of Stroke } \\
\quad(n=18,269)\end{array}$ & $\begin{array}{l}\text { No History of Stroke } \\
\quad(n=421,897)\end{array}$ \\
\hline & & \multicolumn{3}{|c|}{$\%$ (95\% Confidence Interval) $^{\text {b }}$} \\
\hline Consumes $\geq 1$ fruit and $\geq 1$ vegetable daily ${ }^{c}$ & 381,649 & $51.8(51.5-52.1)$ & $45.2(41.9-48.6)$ & $52.0(51.7-52.4)$ \\
\hline Meets weekly aerobic PA recommendations ${ }^{d}$ & 387,150 & $50.6(50.2-50.9)$ & $42.5(39.2-45.9)$ & $50.9(50.6-51.2)$ \\
\hline Has a $\mathrm{BMI}<25 \mathrm{~kg} / \mathrm{m}^{2 \mathrm{e}}$ & 403,977 & $35.8(35.5-36.1)$ & $33.0(29.9-36.1)$ & $35.9(35.6-36.2)$ \\
\hline
\end{tabular}

Abbreviations: BMI, body mass index; PA, physical activity.

${ }^{a}$ Unweighted number of respondents. The number of respondents with each healthy behavior is reported.

${ }^{\mathrm{b}}$ Estimates are weighted and age-adjusted to the 2000 US standard population.

${ }^{c}$ Respondents were asked to indicate how many times per day, week, or month (during the previous month) they consumed fruit, $100 \%$ fruit juice, beans, and vegetables.

${ }^{\mathrm{d}}$ Weekly aerobic physical activity recommendations include $\geq 150 \mathrm{~min}$ of moderate-intensity PA per week, $\geq 75$ min of vigorous-intensity PA per week, or an equivalent combination of moderate- and vigorous-intensity PA per week.

${ }^{\mathrm{e}} \mathrm{BMI}\left(\mathrm{kg} / \mathrm{m}^{2}\right)$ was calculated using self-reported weight and height at the time of survey.

The opinions expressed by authors contributing to this journal do not necessarily reflect the opinions of the U.S. Department of Health and Human Services, the Public Health Service, the Centers for Disease Control and Prevention, or the authors' affiliated institutions. 
Table 3. Prevalence of Number of Healthy Behaviors Among US Adults, by History of Stroke Status, Behavioral Risk Factor Surveillance System, 2015

\begin{tabular}{|c|c|c|c|c|}
\hline \multirow[b]{2}{*}{ Number of Healthy Behaviors ${ }^{a}$} & \multirow{2}{*}{$\begin{array}{l}\text { Number of } \\
\text { Respondents }\end{array}$} & Total & $\begin{array}{l}\text { History of Stroke } \\
(n=13,917)\end{array}$ & $\begin{array}{l}\text { No History of Stroke } \\
(n=333,013)\end{array}$ \\
\hline & & \multicolumn{3}{|c|}{$\%(95 \% \text { Confidence Interval })^{c}$} \\
\hline 0 & 63,895 & $19.0(18.8-19.3)$ & $24.8(22.2-27.5)$ & $18.8(18.6-19.1)$ \\
\hline 1 & 120,379 & $35.8(35.5-36.2)$ & $36.4(33.1-39.6)$ & $35.8(35.4-36.1)$ \\
\hline 2 & 115,397 & $32.6(32.3-32.9)$ & $30.8(27.3-34.3)$ & $32.8(32.4-33.1)$ \\
\hline 3 & 47,259 & $12.5(12.3-12.8)$ & $8.1(5.9-10.2)$ & $12.7(12.4-12.9)$ \\
\hline
\end{tabular}

${ }^{a}$ The number of healthy behaviors (ie, consumes $\geq 1$ fruit and $\geq 1$ vegetable daily, meets weekly aerobic physical activity recommendations, has a body mass index $<25 \mathrm{~kg} / \mathrm{m}^{2}$ ) was computed for each respondent by summing the number of individual healthy behaviors. Only respondents who provided data for all 3 healthy behaviors were included in the analysis.

${ }^{\mathrm{b}}$ Unweighted number of respondents.

${ }^{c}$ Estimates are weighted and age-adjusted to the 2000 US standard population. 